\title{
MICROMACHINED CHEMICAL REACTORS FOR SURFACE CATALYZED OXIDATION REACTIONS
}

\author{
Ravi Srinivasan ${ }^{\dagger}$, I-Ming Hsing ${ }^{\dagger}$, J. Ryley ${ }^{*}$, M.P. Harold ${ }^{*}$, K.F. Jensen ${ }^{\dagger}$, and \\ M. A. Schmidt ${ }^{\ddagger}$

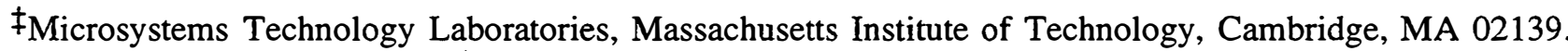 \\ tDepartment of Chemical Engineering, MIT. \\ * Dupont Central Research \& Development, Experimental Station, Wilmington, DE 19880.
}

\begin{abstract}
A micromachined chemical reactor ( $\mu$-reactor) for performing highly exothermic heterogeneous catalytic reactions has been fabricated, and successfully tested for two gas-phase model reaction systems- $\mathrm{CO}$ and $\mathrm{NH}_{3}$ oxidations over $\mathrm{Pt}$ catalyst. The results demonstrate the feasibility of chemical production on a micro-scale, and suggest that $\mu$-reactors have the potential of safer operation as compared to conventional reactors.
\end{abstract}

\section{INTRODUCTION}

Micromachined chemical systems have traditionally been fabricated for chemical analysis and sensing, not chemical production. Recent reports have outlined the potential advantages of micromachined chemical systems for chemical production $[\mathbf{1 , 2}]$, and have demonstrated feasibility of conducting reactions in externally heated microchannels [1]. One promising advantage of micromachined chemical reactors over conventional reactors is the increased safety for carrying out highly exothermic reactions that could lead to thermal runaway and explosions in conventional reactors. By carrying out the reaction in small physical dimensions, i.e. increasing the surface area to volume ratio of the reactor, heat can be removed very efficiently from the reactor, potentially preventing a thermal runaway. Moreover, the large surface area to volume ratios serves to inhibit undesired gas phase chemistry by thermal or chemical quenching of free radicals, thus preventing a gas-phase chain branching type of runaway reaction.

The aim of this research is to understand and to explore the fundamental issues in carrying out a particular class of exothermic reactions on a micro-scale, namely catalytic partial oxidation reactions. Partial oxidation reactions are widely used in the chemical industry to produce a large number of useful chemical intermediates such as alcohols, aldehydes, cyanides, and nitriles [3]. These partial oxidation reactions are typically extremely fast and highly exothermic (heats of reaction on the order of $100 \mathrm{~kJ} / \mathrm{mol}$ ). These characteristics make the control of conventional 'macroscopic' partial oxidation reactors difficult. Slight changes in reactor parameters such as the inlet temperature can cause a runaway reaction, potentially leading to an explosion. Thus, these reactions are ideal candidates for exploring potential safety advantages of micromachined reactors.

Commercially, $\mu$-reactors could be used for point of use production of toxic or unstable chemicals via partial oxidation reactions. This would eliminate the need for storage and transportation of these hazardous and unstable chemicals [1]. Since some partial oxidation reactions are very fast (reaction time $<1 \mathrm{~ms}$ ), the throughput of one $\mu$-reactor may be sufficiently large that a modest number of $\mu$-reactors operating in parallel could satisfy the requisite production rate for point of use applications. In this paper we will describe our prototype $\mu$-reactor, the test set-up, and initial test results for two model catalytic oxidation reactions.

\section{DEVICE DESCRIPTION}

The $\mu$-reactor is a T-shaped channel for gas flow fabricated by bulk micromachining of a silicon wafer (figs.1\&2). The channel is sealed from the top by a low stress silicon nitride membrane (fig.1), and is sealed at the bottom by an aluminum base-plate with three gas inlet-outlet holes that is epoxied to the chip (fig. 3). Reactant gases enter the $\mu$-reactor at the two ends of the horizontal flow sensor region, where the gas flow rate is determined using hot film anemometer in either a time of flight or anemometer mode. The reactant gases diffusively mix at the entrance to the reaction zone which is the vertical section of the T-shaped channel. In the reaction zone, the gases react on the catalyst that is coated on the silicon nitride membrane, and the products exit the $\mu$-reactor at the vertical end of the $T$.

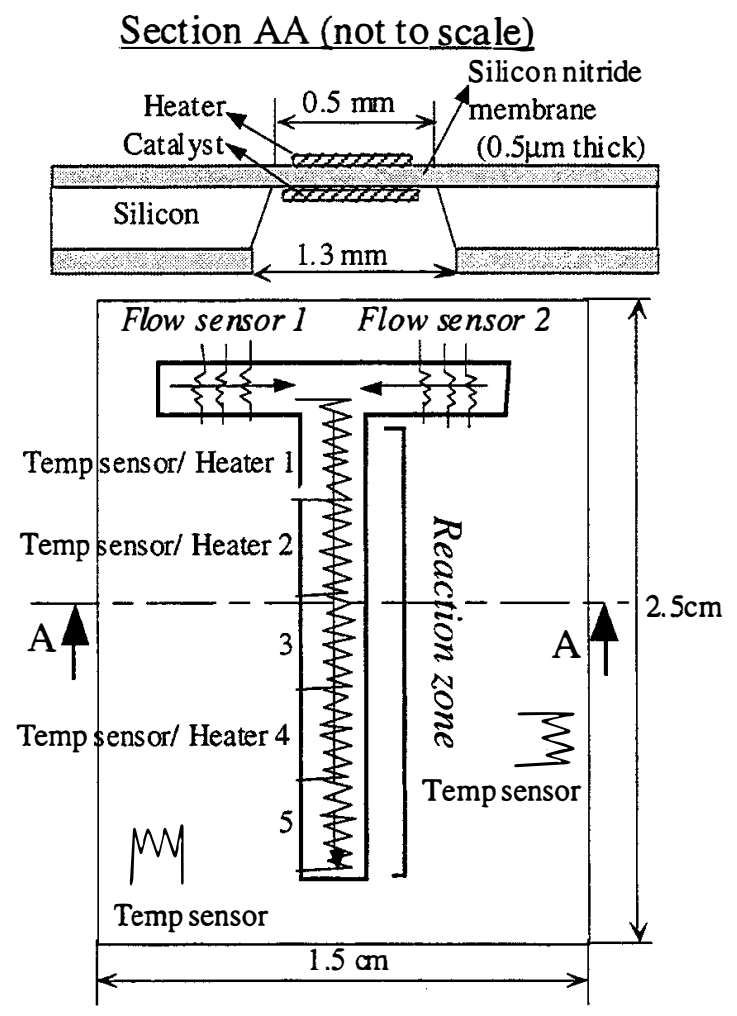

Fig.1 Schematic top-view of $\mu$-reactor 


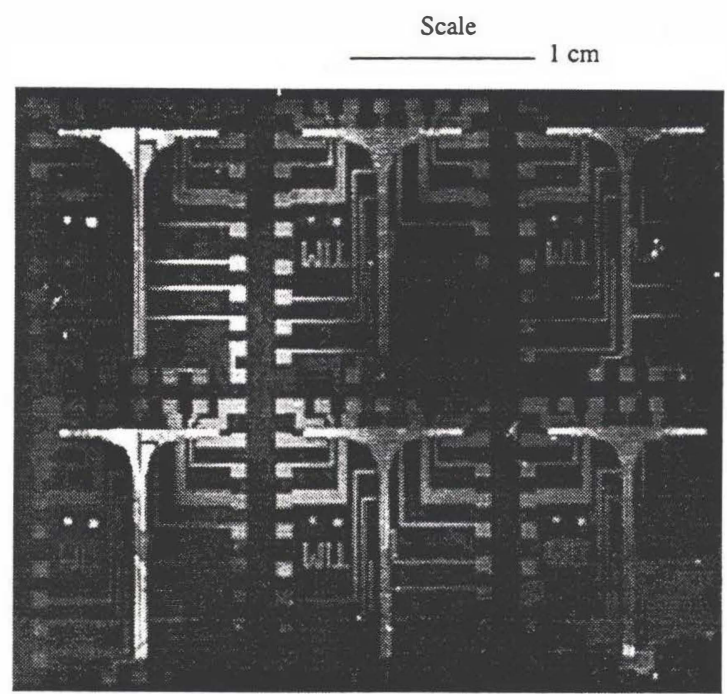

Fig.2 Photograph of part of wafer showing six devices

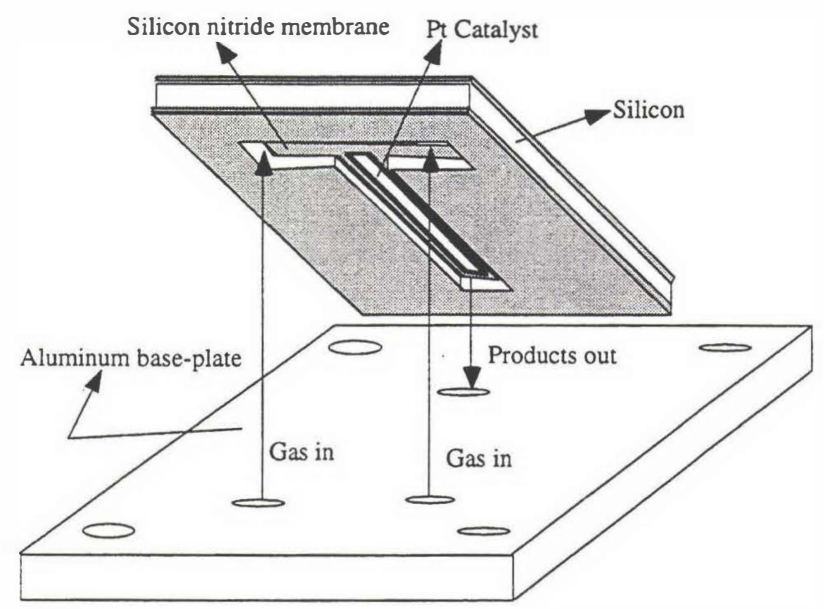

Fig. 3 Exploded view of $\mu$-reactor package

The top surface of the silicon nitride membrane has five segmented $\mathrm{Pt}$ resistor lines, which serve both to heat the catalyst, and to measure its temperature. Heat transfer simulations indicate negligible temperature difference between heater segments on the top surface, and the catalyst on the bottom surface of the membrane. The temperature is determined by measuring the incremental electrical resistance of the heaters, and then comparing the measured value with previously generated calibration curves of incremental resistance with temperature.

\section{FABRICATION PROCESS}

The starting material for the $\mu$-reactor fabrication (fig. 4) was a double side polished $(100 \mathrm{~mm}$ diameter , $550 \mu \mathrm{m}$ thick) silicon wafer LPCVD coated with $0.5 \mu \mathrm{m}$ thick low-stress silicon nitride. The backside of the wafer was patterned and plasma etched to expose the silicon in the T-shaped channel region. The front side of the wafer was then patterned for metal lift-off using infra-red (IR) alignment. E-beam evaporation of $0.1 \mu \mathrm{m}$ platinum (on a $10 \mathrm{~nm} \mathrm{Ti}$ adhesion layer)

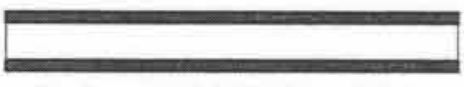

Starting material- Double polished

Si wafer with CVD nitride

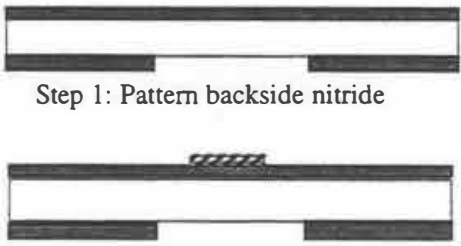

Step 2: Deposit and pattern metal on frontside

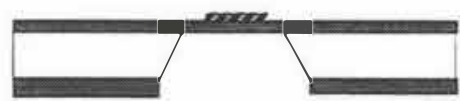

Step 3: $\mathrm{KOH}$ etch channels
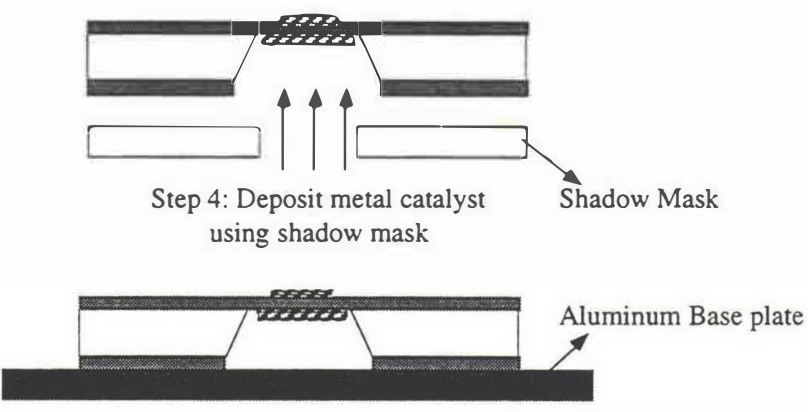

Step 5: Epoxy Al base-plate to seal channel

Fig. 4 Fabrication Process Flow

for metal heaters, and temperature and flow sensors was carried out. In the next step, the backside of the wafer was exposed to $\mathrm{KOH}$, etching the bulk of silicon, stopping on the nitride membrane. Subsequently, $0.1 \mu \mathrm{m}$ thick platinum catalyst (on $10 \mathrm{~nm} \mathrm{Ti}$ ) was e-beam deposited on the silicon nitride membrane in the reactor region via a shadow mask. In the final step, an aluminum base-plate with three gas inletoutlet holes was epoxied to the chip (figs.3\&4).

\section{TEST SETUP}

The test-bed for the $\mu$-reactor is shown in fig.5. $\mathrm{O}_{2}, \mathrm{NH}_{3}$ and $\mathrm{CO}$ were transported via external mass flow controllers, which maintain the desired gas flow rates, into a mechanical package (gas input-output chuck). The gas input-output chuck was used to transfer gases from the external 1/16" piping into the $\mu$-reactor. The gas inlet-outlet holes in the $\mu$-reactor baseplate were aligned with the gas inlet-outlet holes in the chuck, and the base-plate was sealed by pressurized contact with Viton ${ }^{\circledR}$ o-rings on the top face of the chuck.

A probe card was used to electrically access the heater and temperature sensor bond pads. The product gas stream exited the $\mu$-reactor via the gas input-output chuck outlet into the exhaust piping. The exhaust gas concentrations were continuously monitored using a quadrupole mass spectrometer. The $\mu$-reactor assembly was placed under a microscope for imaging. 


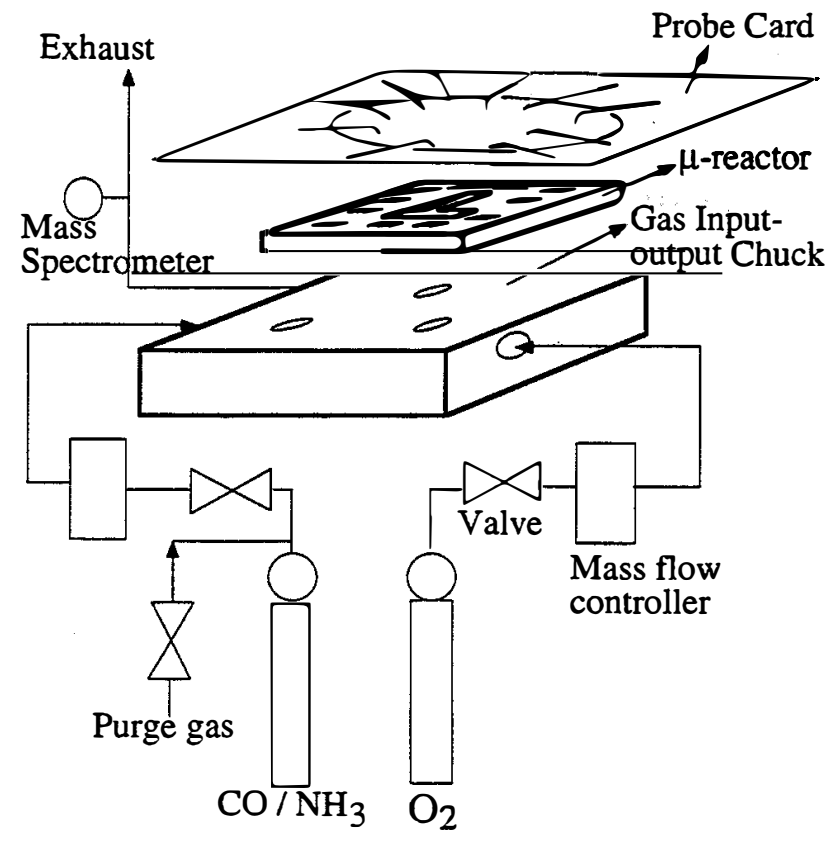

Fig. 5 Schematic diagram of $\mu$-reactor test-bed

\section{DEVICE MODELING}

We have developed two and three dimensional Galerkin Finite Element (FEM) simulation tools for evaluating and comparing $\mu$-reactor performance with conventional reactors based on similar modeling tools for microelectronics processing[6]. A mesh generator is used to translate reactor geometries into FEM meshes. As an example of the three dimensional fluid flow and heat transfer simulations, fig.6 shows the temperature profile on the silicon nitride membrane, and fig. 7 displays the corresponding temperatures in the gas below the heater in the reaction zone. The very good thermal isolation provided by the silicon nitride membrane results in a very narrow hot zone, while the bulk of the $\mu$-reactor chip is at room temperature.

Detailed chemical mechanisms have been coupled with fluid flow, heat and mass transfer FEM simulations to evaluate the chemical behavior of $\mu$-reactors, specifically their ability to prevent runaway reactions and their product yield and selectivity. The computations show that the heat transfer to the bulk Si wafer and wall quenching reactions have the desired effect of eliminating thermal runaway.

\section{TEST RESULTS}

The $\mu$-reactor operation has been successfully tested for two catalytic oxidation reactions: 1) $\mathrm{Pt}$ catalyzed oxidation of $\mathrm{NH}_{3}$,

$$
\mathrm{NH}_{3}+\frac{.5}{4} \mathrm{O}_{2} \stackrel{\mathrm{Pt}}{\longrightarrow} \mathrm{NO}+\frac{3}{2} \mathrm{H}_{2} \mathrm{O}+226 \mathrm{~kJ}
$$

and 2) $\mathrm{Pt}$ catalyzed oxidation of $\mathrm{CO}$,

$$
\mathrm{CO}+\frac{1}{2} \mathrm{O}_{2} \stackrel{\mathrm{Pt}}{\longrightarrow} \mathrm{CO}_{2}+284 \mathrm{~kJ} \text {. }
$$

The mass spectrometer data of the normalized $\mathrm{NH}_{3}$ peak, in the case of the $\mathrm{NH}_{3}$ oxidation reaction is shown in fig.8. The 2nd heater segment of the $\mu$-reactor (fig. 1 ) was gradually heated under gas inlet conditions summarized in fig.8. The reaction ignited at a catalyst temperature of $230^{\circ} \mathrm{C}$, as

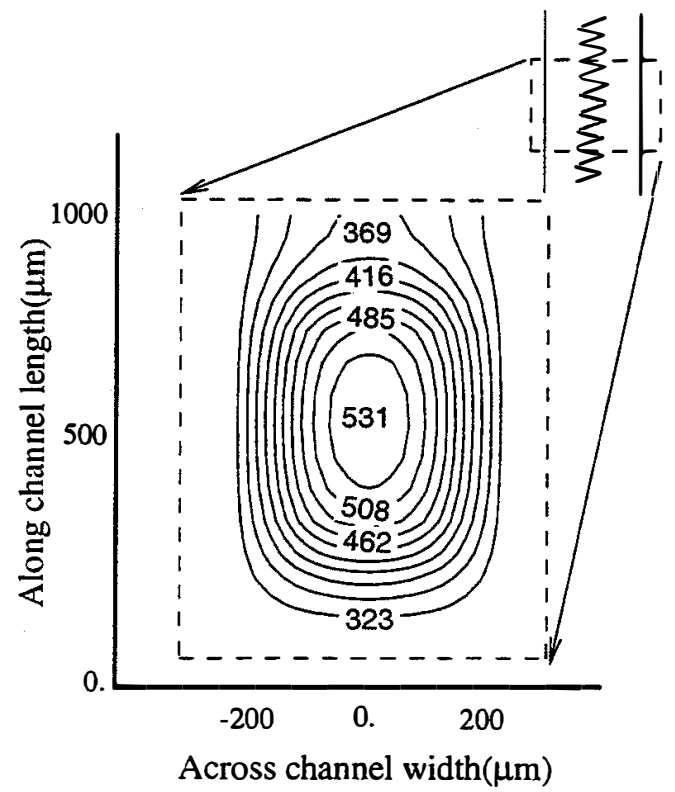

Fig. 6. Temperature contours on SiN membrane. The figure inset shows the active heater segment on the SiN membrane that was used in the simulation.

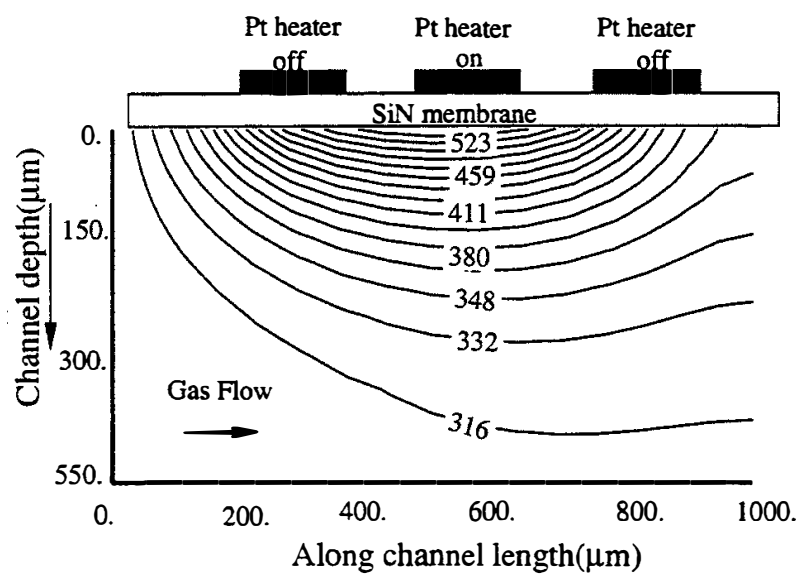

Fig. 7 Temperature profile along reactor length. The gas flow velocity is $26 \mathrm{~cm} / \mathrm{s}$.

indicated by the drop in the $\mathrm{NH}_{3}$ peak intensity. Once ignited, the power to the heater was kept constant, but the catalyst temperature rapidly climbed to a steady state value of $680^{\circ} \mathrm{C}$ due to the heat released by the reaction. The NO peak in the mass spectrometer signal rose while the $\mathrm{N}_{2}, \mathrm{~N}_{2} \mathrm{O}$ and $\mathrm{NO}_{2}$ peaks were absent, indicating that there were no side reactions. For this reaction, the catalyst activity remained stable over several hours of operation.

Mass spectrometer data of the exhaust gas stream in the $\mathrm{CO}$ oxidation reaction is shown in fig.9. The reaction ignited at a catalyst temperature of $400^{\circ} \mathrm{C}$ (at $\mathrm{t}=150 \mathrm{~s}$ in fig.7), as indicated by the drop in $\mathrm{CO}$ concentration and rise in the $\mathrm{CO}_{2}$ concentration in the product gas stream. The catalyst temperature rapidly climbed to $800^{\circ} \mathrm{C}$ as a result of the heat 


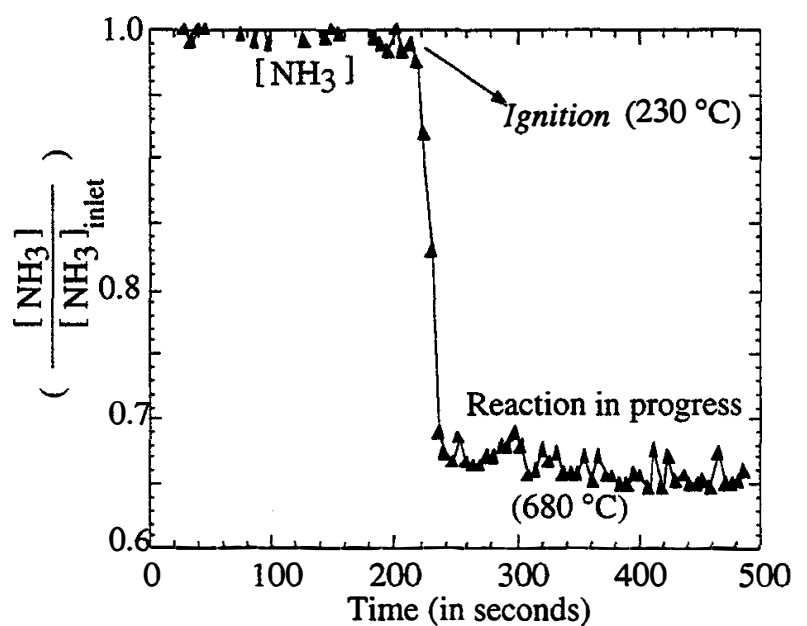

Fig. 8 Normalized concentrations of $\mu$-reactor exhaust during $\mathrm{NH}_{3}$ oxidation. Reaction conditions are-Pressure = latm, inlet $\mathrm{O}_{2}$ flowrate $=10 \mathrm{sccm}$, inlet $\mathrm{NH}_{3}$ flowrate = $1 \mathrm{sccm}$, Power supplied to heater at ignition $=124.5 \mathrm{~mW}$.

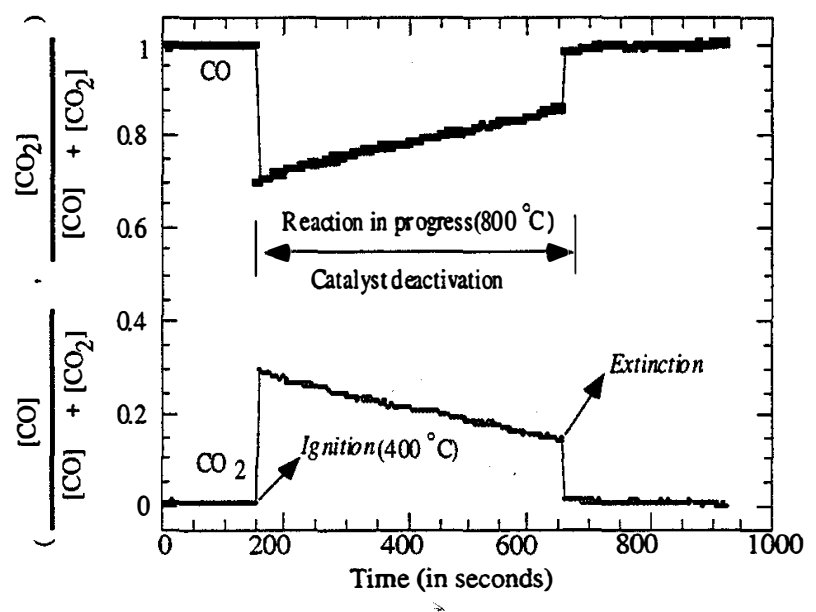

Fig. 9 Normalized concentrations of $\mu$-reactor exhaust during $\mathrm{CO}$ oxidation. Reaction conditions are-Pressure $=$ Iatm, inlet $\mathrm{O}_{2}$ flowrate $=20 \mathrm{sccm}$, inlet $\mathrm{CO}$ flowrate $=2 \mathrm{sccm}$, Power supplied to heater at ignition $=340 \mathrm{~mW}$.

released in the reaction. This ignition behavior is consistent with $\mathrm{CO}$ oxidation literature[4]. As the reaction progressed, the catalyst deactivated leading to a steady drop in the reaction rate, and eventual extinction of the reaction. Ex-situ Auger Electron Spectroscopy of the catalyst surface revealed carbon and nickel deposits as possible causes for the catalyst deactivation.

Several observations may be made when comparing the reported behavior of $\mu$-reactor test data with macroscopic laboratory reactors operating with the same inlet gas compositions. The ignition behavior is the same, but the reaction and extinction behavior in the $\mu$-reactor deviated from conventional laboratory reactors. When catalytic $\mathrm{NH}_{3}$ oxidation is carried out on Pt foils suspended in a $3.2 \mathrm{~cm}$ diameter pyrex tube, under the same inlet gas conditions as the present study, the reaction is autothermal [5], i.e. it does not require external heat input to sustain the reaction and can only be shut off by stopping the flow of reactants. In contrast, in the $\mu$-reactor, the reaction extinguishes at heater powers below $118 \mathrm{~mW}$. Thus, in the event of an emergency, the $\mu$-reactor can be shut-off immediately by turning off the heaters, leading to safer operation.

\section{CONCLUSION}

A promising application for micromachined chemical reactors is the processing of potentially explosive and hazardous reactions. A $\mu$-reactor for carrying out an important class of highly exothermic hydrocarbon partial oxidations, has been fabricated, and successfully tested for two model reaction system. Preliminary results demonstrate the feasibility of conducting catalytic reactions on a micro-scale, and more importantly, indicate a potential for safer operation of $\mu$-reactors over conventional reactors.

\section{ACKNOWLEDGMENTS}

We thank Dupont and the NSF PYI award program (Martin Schmidt) for funding this work. We also gratefully acknowledge the help of MTL staff, Dupont staff (Mark Wetzel and Jim Ashmead), and students of MAS and KFJ groups at MIT.

\section{REFERENCES}

[1] J.J. Lerou, M.P. Harold, J. Ryley, J. Ashmead, T.C. O’Brien, M. Johnson, J. Perrotto, C.T. Blaisdell, T.A. Rensi, and J. Nyquist, "Microfabricated Minichemical Systems: Technical Feasibility," To be published in the proceedings of the workshop on, Microsystem Technology for Chemical and Biological Microreactors, Max-Planck-Institut, Mainz, Germany, 1995.

[2] H. Mobius, W. Ehrfeld, V. Hessel, Th. Richter, "Sensor controlled processes in chemical microreactors," Proceedings of The 8th International Conference on SolidState Sensors and Actuators, 775 (1995).

[3] C.N. Satterfield, "Heterogeneous Catalysis in Industrial Practice," 2nd Edition, McGraw-Hill Inc., New York (1991).

[4] L.F. Razón and R.A. Schmitz, "Intrinsically unstable behavior during the oxidation of carbon monoxide on platinum," Cat. Rev. Sci. Engng, 28, 89 (1986).

[5] W.R. Williams, M.T. Stenzel, X. Song, and L.D. Schmidt, "Bifurcation Behavior in Homogeneous-Heterogeneous Combustion: I. Experimental Results Over Platinum," Combustion and Flame, 84, 277 (1991).

[6] K.F. Jensen, T.P. Merchant, J.V. Cole, J.P. Hebb, K.L. Knutson, and T.G. Mihopoulos, "Modelling Strategies for Rapid Thermal Processing", in Advances in Rapid Thermal and Integrated Processing, (Ed. F. Roozeboom), Kluwer, The Netherlands (1996). 